\title{
Construction of the Regional Service Platform for Knowledge Sharing of Scientific and Technological Information
}

\author{
Xin $\mathrm{Li}^{1, \mathrm{a}}$ and Bo Guan ${ }^{1, \mathrm{~b}}$ * \\ ${ }^{1}$ Library, Beihua University, Jilin, China \\ ${ }^{2}$ Public Language Institute, Beihua University, Jilin, China \\ alixin198282@163.com, b304230443@qq.com \\ * Corresponding author
}

Keywords: Platform construction; Science and technology sharing; Information navigation

\begin{abstract}
Purpose/significance] In the era of big data information, the number of scientific and technological information as the first productivity increases rapidly. At present, the urgent problem for information service workers is to improve the quantity of scientific and technological information transformation. [Method/process] This paper analyzes the current situation of science and technology information in specific region, and the platform for the construction of the main content and the key influence, sorting and screening of high quality information in the region, choosing the right organization and storage technology, achieving orderly organization, navigation and dissemination of scientific and technological information resources. [Result/conclusion] Construction of sharing service platform for scientific and technological resources, actively promote the quality of the information technology in the region, giving full play to the advantages of scientific and technological information, improving the conversion rate of achievements. It provides a powerful source of scientific and technological power and information service support for regional economic construction.
\end{abstract}

\section{Introduction}

The ubiquitous network environment, with the development of information age and knowledge economy, technological innovation has become the leading role of the more obvious, science and technology resources possession, configuration, development, exchange and use of the advantages and disadvantages, has increasingly become the key factor to decide a country or regional core competitiveness. The basic condition of science and technology supporting the progress and innovation of science and technology has risen to be an important strategic resource. In the construction of basic conditions of science and technology, the guarantee and service ability of science and technology information resources has also become an important factor of great concern. In this context, it is necessary to explore and strengthen the construction of regional science and technology information resources guarantee and service capacity, to promote the establishment of strategic alliances, and to build the joint service system of regional science and technology information.

With the continuous development of digital and information technology, the transformation of scientific and technological information results in the role of social and economic construction is becoming more and more important. The university is the most intensive activities for innovative talents, scientific research of University Science and technology workers is an important source of new information, new knowledge, new achievements, scientific research and production workers to grasp the latest achievements of science and technology information. Big data in the information age, the rapid growth of information technology as the first productivity number, how to improve the knowledge of science and technology achievements transformation and information sharing is the key problem of the current workers in science and technology information service urgent. Through the visualization of knowledge navigation technology to publish and share, so as to give full play to the scientific and technological advantages of innovative talents, it is a resource sharing problem which needs to be solved urgently in the information society environment. 


\section{Present situation research}

Western developed countries have always attached great importance to the research and construction of the joint service system of science and technology information resources, especially the literature information resources in Europe and other countries sharing network is now connected with most of the information service institution throughout the country and the region, range and depth of resource sharing have reached a considerable degree. The concept of this development is that the information users of science and technology can make use of the information resources and services provided by the various documents and information institutions in any place and at any time. It is also such a development that lays the foundation for the development and construction of ubiquitous knowledge environment and more efficient scientific and technological innovation system and mechanism.

Domestic, the construction of science and technology information digitization has been widespread attention of the relevant departments in Colleges and universities. After years of construction, the digital platform of science and technology information has made great progress. National Science and Technology Library and documentation center and Tsinghua University have carried out research and development of the national literature platform. In addition, the late construction of these platforms has financial support, advanced technology and equipment, good service conditions, their scientific and technological literature platform construction and service in the forefront of the country. Other areas of science and technology information resources sharing platform construction can not be compared with its development has certain relativity and limitations, whether it is the construction situation or the use of circumstances, need to be improved.

\section{Problems existing in scientific and technological information platform at present}

At present, the construction of scientific and technological information platform is relatively huge, especially for enterprises, it needs high-quality scientific and technological information resources, but the current development is not satisfactory.

The sharing of science and technology information resources can not be effectively realized.

Sharing coordination mechanism is not perfect, the construction of sharing platform, the lack of unified planning and coordination, in a state or simply fight the enemy separately, cooperation is very loose, just rely on a cooperation agreement and the Council Regulation self-discipline, no mandatory obligation nor the legal level of rights, resulting in science and technology information resources of decentralized, repeat, overall advantage it is difficult to form a service. At present, the scientific and technological information resources of colleges and universities have made due contributions to the development of enterprises, but there still exist problems of low utilization efficiency.

The service efficiency can not be maximized.

The platform of science and technology information resources in Colleges and universities is based on the integration of different university science and technology information resources, but the construction of standardized platform has not been completely standard, this is because the platform is based on the standards of "low standards, inconsistent standards and other aspects of the problem, which is mainly manifested in the overall design framework, technical means the use of database construction, etc., this is a direct result of its inability to maximize the effectiveness of the services.

\section{The content of the construction of regional science and technology information integrated service platform}

Service capability determines the level of science and technology platform for the construction of the sharing of information resources, science and technology information resource sharing platform service ability, to improve the sharing platform utilization, and finally realize the steady and sustainable development of the sharing platform. In order to realize the leap of service ability, it is necessary to innovate the service concept, service content and service mode of scientific and technological information resource sharing platform. 
The construction of regional science and technology information integrated service platform, the main construction contents are: Science and technology information system construction, information technology, science and technology information acquisition module construction organization storage module, navigation module and the characteristics of information technology combined with the construction of the service system.

System construction of science and technology information. In the aspect of system development platform, at least to consider two points: one is in the choice of technology should be considered to be advanced, maturity and practicability and technology; two is in the design of system function, must be considered to provide for local and remote construction function support, support network cooperation, support member unit cooperation business, workflow management, support resources have rules and quality examination, statistics and analysis of the volume of business support. In addition, the system platform should support the further thematic organization and disclosure of information resources, and support the response of personalized customization and push service requests.

Collection module of science and technology information. The category of science and technology information mainly includes the achievements of related research projects, academic research papers and practical patent information in the process of regional personnel experiment research. It is the achievement record and value embodiment of scientific and technological activities of scientific research workers. It is the crystallization of human wisdom. Scientific and technological information is transformed into scientific and technological productivity through the results, so as to promote the development of regional economy. Colleges and universities are not only the place where scientific and technological talents are gathered, but also the bases for training excellent talents and scientific and technological innovation teams.

In the process of collecting information, for the science and technology information source different forms, we through the scanning input and character recognition and other big data technology into the digital platform can be unified storage and data records, strategy according to subject classification and hierarchical classification by screening, collection and classification of information.

Organization and storage module of scientific and technical information. In order to better display the mass information source to the readers, it is necessary to organize and store the collection of scientific and technical information. The storage format of relational database is relatively simple, and it is the most effective method for knowledge organization and marking of scientific and technological information. Relational database is a description storage structure of field attribute values by defining objects and objects as different attributes as fields.

The value of the attribute information of research achievements including the research project name, subject classification, the members of the project group, project department, project department, project approval, project approval time time, achievement level, achievement and project funding attribute field. The attribute values of practical patent information include the patent name, patent number, subject, completion personnel, completion unit, type of property rights, application time, authorization state and authorization time.

Navigation and sharing module of science and technology information. The knowledge navigation module by using visual navigation tools, a release and push strategy visual description of recording information stored in the database, using the computer program design and multimedia display method combining the technology of knowledge. Knowledge navigation model visualization includes two processes, the first process is the use of computer "display technology, reading and retrieving information recorded in the database platform, convenient for users to browse and use; the second process is through the use of complex network technology folksonomy, to find the relationship between clustering and information technology, through the visual interface label emerges and guide the user to the knowledge discovery process.

Construction of consolidation service. With the diversification and complexity of users' information needs, it is obviously not realistic to rely on the power of one family to meet the needs of many users. Therefore, it is very important to actively promote regional service integration and capacity integration, and establish a joint service system under the guarantee of a certain mechanism. In the construction of 
regional science and technology information joint service system, we should emancipate the mind, dare to break the shackles of traditional ideas, through mechanism innovation, establish a cross system, cross industry cooperation organization.

\section{Summary}

In the era of big data information, the number of scientific and technological information as the first productivity increases rapidly. At present, the urgent problem for information service workers is to improve the quantity of scientific and technological information transformation. This paper analyzes the current situation of science and technology information in specific region,and the platform for the construction of the main content and the key influence, sorting and screening of high quality information in the region, choosing the right organization and storage technology, achieving orderly organization, navigation and dissemination of scientific and technological information resources. Construction of sharing service platform for scientific and technological resources, actively promote the quality of the information technology in the region, giving full play to the advantages of scientific and technological information, improving the conversion rate of achievements. It provides a powerful source of scientific and technological power and information service support for regional economic construction.

\section{Acknowledgements}

This paper is the relevant research result of the Educational Science Program in Jilin Province " Research on the teaching model reform of Library Literature Retrieval Course under the prosperity of network culture"(project number: GH170053); This paper is the relevant research result of the Teaching and research project of Beihua University (project number: XJQN2017011).

\section{References}

[1] B.L. Hua: Library and Information Service, Vol:61(2017)No.16,P.1-6. (In Chinese)

[2] H.W. Jin and Y. Yuan: Information Science, Vol:33(2015)No.05,p.58-62.(In Chinese)

[3] S.K. Zhao and D.W. Zhang: Library and Information Service, Vol:59(2015)No.05,p.40-46. (In Chinese)

[4] L. Qin, X.Y. Wang and J.W. Zhao: Information Studies:Theory \& Application, Vol:38(2015)No.01,p.18-22. (In Chinese)

[5] L.X. Yang and L.N. Wang: Library and Information Service, Vol:57 (2013)No.16,p.46-50. (In Chinese)

[6] S. Yang, X.Q. Jia and Z.Q. Zhou: Information Science,Vol:31(2013)No.07,p.144-149. (In Chinese)

[7] J. Zhang: Research on Library Science, (2012)No.13,p.41-46. (In Chinese)

[8] W.W. Zhang: Information Science,Vol:28(2010)No.09,p.1314-1318. (In Chinese)

[9] S.H. Tang: Information Studies:Theory \& Application,Vol:32(2009)No.03,p.42-46. (In Chinese)

[10]X.N. Wu, Z.M. Zhu and Z.Q. Zhang: Library Theory and Practice,(2008)No.05:94-97. (In Chinese) 